\title{
Design and Function of a New Conical Positive Expiratory Pressure Device to Be Used During Exercise
}

\author{
Chatchai Phimphasak PT, Chulee Ubolsakka-Jones PhD PT, and David A Jones PhD
}

BACKGROUND: A flow-dependent conical positive expiratory pressure (PEP) resistor incorporated into a oronasal mask was developed, which might reduce dyspnea and dynamic hyperinflation and increase exercise endurance for patients with COPD. We reported here the flow-pressure relationships and the safety and suitability of the device when used by healthy young and older subjects. METHODS: The flow-pressure relationships were determined for a range of resistors with different orifice diameters and cone lengths. A 1-cm conical-PEP device with a 6- or 7-mm orifice was used during a cycle exercise test $(60 \%$ heart rate reserve) in 15 young (mean $\pm \mathrm{SD}, 24.3 \pm 3.9$ y) and 12 older (mean \pm SD, $64.4 \pm 3.5$ y) adults. Cardiopulmonary function and dyspnea were monitored for up to $10 \mathrm{~min}$ of exercise. RESULTS: For a given flow, pressure decreased as the cone length and orifice size increased. A $1-\mathrm{cm}$ cone with a $6 \mathrm{~mm}$ orifice generated pressures of $5.24 \pm 0.17$ $\mathrm{cm}_{2} \mathrm{O}$ and $18.29 \pm 0.34 \mathrm{~cm} \mathrm{H}_{2} \mathrm{O}$ at flows of 0.5 and $0.9 \mathrm{~L} / \mathrm{s}$, while for a $7 \mathrm{~mm}$ orifice, pressures were $4.88 \pm 0.13 \mathrm{~cm} \mathrm{H}_{2} \mathrm{O}$ and $19.14 \pm 0.10 \mathrm{~cm} \mathrm{H} \mathrm{H}_{2} \mathrm{O}$ at flows of 0.5 and $1.1 \mathrm{~L} / \mathrm{s}$, such as might occur during exercise. The choice of orifice size for a subject depended on his or her estimated expiratory flow; larger flows required the larger orifice to generate an expiratory pressure of between 5 and $20 \mathrm{~cm} \mathrm{H}_{2} \mathrm{O}$. Breathing with the conical-PEP device did not affect exercise time, dyspnea, minute ventilation, heart rate, or blood pressure. The $\mathrm{S}_{\mathrm{pO}_{2}}$ was slightly lower and $\mathrm{P}_{\mathrm{ETCO}_{2}}$ was somewhat higher than during control exercise, but the differences were not significant. There were no adverse physiological consequences. CONCLUSIONS: A conical-PEP device of 1-cm length with an orifice of 6 or $7 \mathrm{~mm}$ generates effective expiratory pressure for most subjects during exercise. There were no adverse effects in healthy young and older subjects, and the device is suitable for trials with patients with COPD. (ClinicalTrials.gov registration NCT 02788370.) Key words: pressure-flow relationship; PEP device; exercise; cardiopulmonary function; randomized trial; physiotherapy. [Respir Care 2018;63(8):966-980. (C) 2018 Daedalus Enterprises]

\section{Introduction}

Pulmonary rehabilitation for patients with COPD generally includes a large component of graded exercise training, which has proven benefits for improving exercise ca-

\footnotetext{
Mr Phimphasak and Dr Ubolsakka-Jones are affiliated with the School of Physical Therapy, Faculty of Associated Medical Sciences, Khon Kaen University, Khon Kaen, Thailand. Dr Jones is affiliated with the Division of Health Science, School of Health Sciences, Manchester Metropolitan University, Manchester, United Kingdom.
}

Funding provided by The Royal Golden Jubilee PhD Program of The Thailand Research Fund and Faculty of Associated Medical Sciences, Khon Kaen University. pacity, breathlessness, the number of exacerbations, days in the hospital, anxiety, depression, and health-related quality of life. ${ }^{1}$ Within sensible limits, the benefits are in proportion to the amount of exercise, so it is important to find ways of maximizing exercise time. During exercise or physical activity, patients with COPD commonly de-

\footnotetext{
Previous poster presentations by Mr Phimphasak: The European Respiratory Society International Congress, held September 3-7, 2016, in London, United Kingdom. The 8th Physical Therapy Association of Thailand Conference, held June 20-23, 2016, in Bangkok, Thailand. The 17th Royal Golden Jubilee PhD Program Congress, held June 8-11, 2016, in Pattaya, Chonburi, Thailand.
}

The authors have disclosed no conflicts of interest. 
velop dynamic hyperinflation due to premature airway closure, which leads to abnormal lung mechanics and thus increased work of breathing, with restriction of normal tidal volume expansion and dyspnea during exercise. ${ }^{2}$ This is a major factor that leads to dyspnea and premature termination of exercise and physical activity, ${ }^{3}$ and, consequently, reduces the potential benefits of pulmonary rehabilitation sessions.

Exhalation through a resistance generates a positive expiratory pressure (PEP), which can help maintain open airways and a more even intrapulmonary distribution of ventilation. ${ }^{4}$ PEP is commonly used in respiratory care for airway clearance and to increase ventilation at rest and in a variety of medical and surgical conditions. ${ }^{5}$ There are 2 types of PEP devices. One involves a springloaded resistance or a head of water and provides a constant load that is independent of the flow. ${ }^{6}$ The alternative is a flow-dependent PEP, such as when breathing through an orifice.

There are conflicting reports of the benefits of PEP breathing during exercise. Flow-independent PEP breathing at $5-10 \mathrm{~cm} \mathrm{H}_{2} \mathrm{O}$ has been shown to reduce dynamic hyperinflation ${ }^{7,8}$ and postexercise dyspnea ${ }^{9,10}$ but also to aggravate dyspnea during cycle exercise in patients with COPD. ${ }^{8}$ More recently, PEP was found to increase the 6-min walk distance in subjects with COPD. ${ }^{11,12}$ Flowdependent PEP breathing is reported to reduce dynamic hyperinflation and dyspnea, ${ }^{13}$ and to increase exercise tolerance in patients with COPD. ${ }^{13,14}$ In contrast, Wibmer et al, ${ }^{15}$ by using flow-dependent PEP, found the 6-min walk distance to be reduced.

The conflicting results may, in part, be due to the different types of PEP devices, some of which may not be ideal for use during exercise. Breathing with a pressure threshold, flow-independent PEP device has the disadvantage that there is a period with no flow at the start of expiration as the pressure builds up and requires pressure to be maintained for the whole of the expiration. This may be acceptable when breathing at rest but can be uncomfortable during exercise when the drive to breathe increases. This could deter patients from sustained exercise during pulmonary rehabilitation.

In contrast, flow-dependent PEP may be more suitable to use during exercise because there is never any interruption of the flow. The problem, however, is that, at low flows, the pressure developed may not be sufficient to provide a clinically useful PEP, which will

Correspondence: Chulee Ubolsakka-Jones PhD PT, School of Physical Therapy, Faculty of Associated Medical, Khon Kaen University, Mitraparb Road, Khon Kaen, Thailand 40002. E-mail: joneschulee@gmail.com.

DOI: $10.4187 /$ respcare.06049

\section{QUICK LOOK}

\section{Current knowledge}

Dynamic hyperinflation is a major cause of dyspnea that limits exercise in individuals with COPD. Positive expiratory pressure (PEP) can help maintain airway patency and reduce hyperinflation, and, potentially, improve exercise capacity. The problem with threshold PEP devices is that there is a period with no flow at the start and end of expiration, which is uncomfortable during exercise. A flow-dependent device might be the answer but the difficulty is finding a design that provides a useful pressure at low flows but not excessive pressure during peak expiration.

\section{What this paper contributes to our knowledge}

We bench tested a range of designs for a flow-dependent PEP device and concluded that a $1-\mathrm{cm}$ cone with a 6- or 7-mm-diameter orifice provided a clinically useful pressure in the range of flows expected during moderate exercise. Testing in healthy young and older subjects showed that people with lower peak flows should use the smaller orifice. There were no contraindications for its use during exercise, and future trials are warranted.

reduce dynamic airway compression. Therefore, the size of the orifice needs to be carefully chosen so that the pressure is high enough to be useful at low flows yet does not generate too high a pressure during peak expiratory flow.

Padkao et al ${ }^{13}$ developed a simple flow-dependent conical-PEP device held in the mouth, which proved to be effective in reducing dyspnea and dynamic hyperinflation, and increased exercise endurance for subjects with COPD during knee extension exercise. However, it is not known whether the design was optimal or whether it could be incorporated into a oronasal mask that might be more convenient to use in everyday life.

The present study was composed of 3 parts. In the first part, different designs of resistor were tested in a bench rig to determine the pressure-flow relationships, the objective was to find a design that generated clinically useful levels of pressure over a range of flows that might be experienced during exercise. The objective of the second experiment was to determine whether the findings of the bench test were reproduced in young subjects during exercise and whether there were any adverse effects of PEP breathing that could make its use problematic during exercise. Having been reassured as to the safety and acceptability of PEP breathing with young people, the third part of the study involved healthy 

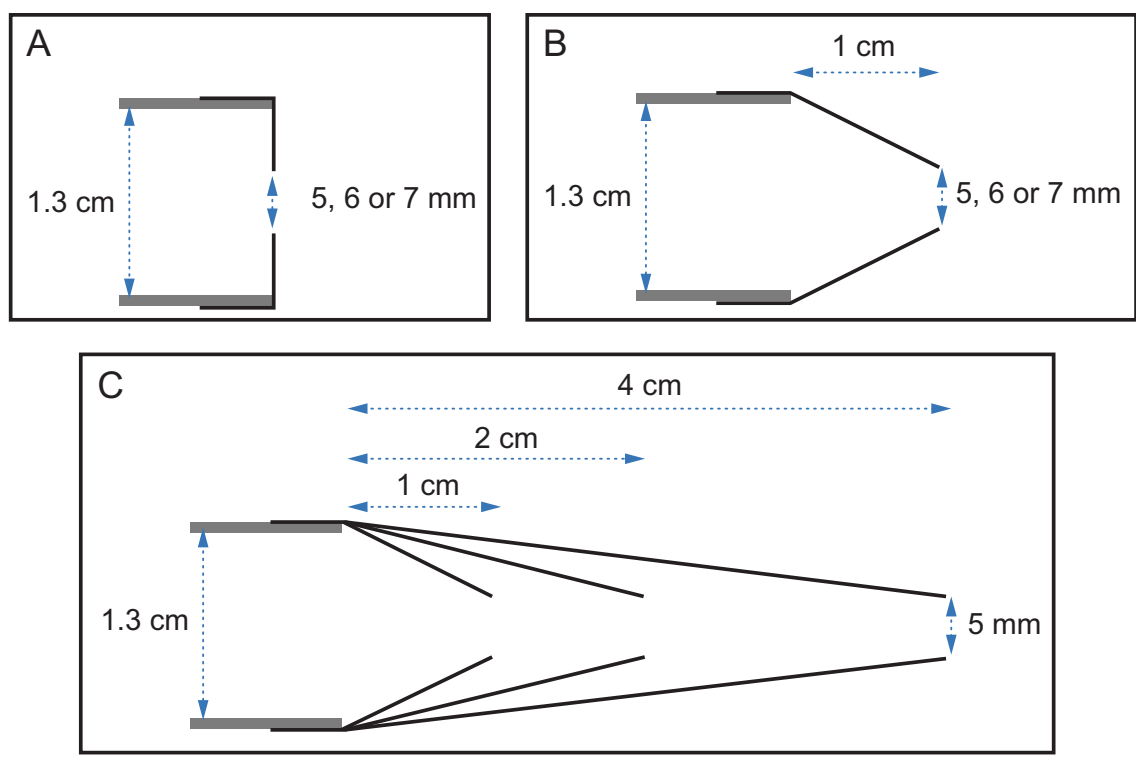

Fig. 1. Positive expiratory pressure (PEP) resistor designs. Plain orifices of different size (A); conical-PEP device with a 1-cm-length cone, with different sized orifices (B); a conical-PEP device with a 5-mm orifice and various cone lengths (C).

older subjects in whom there may be some age-related deterioration of lung function and, possibly, a degree of dynamic hyperinflation during exercise. The objective of this last part was primarily to see if conical-PEP breathing would generate optimum pressures likely to be of clinical importance during exercise and whether it was well tolerated and free of adverse cardiovascular effects.

\section{Methods}

Khon Kaen University Ethics Committee in Human Research approved this study (HE562267). The study was conducted at the School of Physical Therapy, Faculty of Associated Medical Sciences, Khon Kaen University, Khon Kaen, Thailand. All participants gave written informed consent before data collection began.

\section{Experiment 1: Bench Testing of Pressure-Flow Relationships of Different Resistors}

Design of Conical Resistors for a PEP Device. Plain orifice resistors were made by drilling appropriate sized holes into 0.1-mm thick plastic disks (Fig. 1A). Cone resistors were made by rolling $0.1-\mathrm{mm}$ plastic sheets into cones 1,2 , and $4 \mathrm{~cm}$ in length, with orifices of 5,6 , and $7 \mathrm{~mm}$ diameter (Fig. 1B and Fig. 1C).

Pressure-Flow Relationships of Different Resistors. The apparatus used to measure flow and pressure is shown in Figure 2, with transducers connected to a BIOPAC MP 36 system (Biopac Inc., Goleta, Califor- nia). A 30-cm corrugated tube connected the transducer and PEP assembly to a mechanical air pump that could be set to different flows. There was also a bacterial filter to diffuse the air stream, together with Biopac air flow (SS11LA) and pressure (SS13L) transducers situated immediately in front of the PEP device. The flow and pressure transducers were calibrated, and all the connections were carefully checked to make sure that there were no air leaks before the start of every test. Data were collected at $31.25 \mathrm{~Hz}$. The pressures generated by each of the 8 different resistors (Fig. 1) were measured 3 times at each flow, from 0.1 to $1.5 \mathrm{~L} / \mathrm{s}$ in increments of $0.1 \mathrm{~L} / \mathrm{s}$. This range was chosen to cover the likely expiratory flows during exercise in patients with COPD.

\section{Experiment 2: Pressure-Flow Relationships and Cardiopulmonary Responses During Exercise with the Conical-PEP Device in Young Subjects}

Subjects. Twenty-three healthy subjects with normal respiratory function participated in experiment 2.1, and 15 of these continued with experiment 2.2. Details of the subjects are given in Table 1 . The subjects were recruited from the university population. The studies were of a crossover design, with randomized allocation to exercise with a 1-cm conical-PEP device with a 6- or 7-mm orifice for experiment 2.1, and to exercise with a suitable conical-PEP device and without the PEP device (sham) for experiment 2.2. 


\section{Conical PeP Device During Exercise}

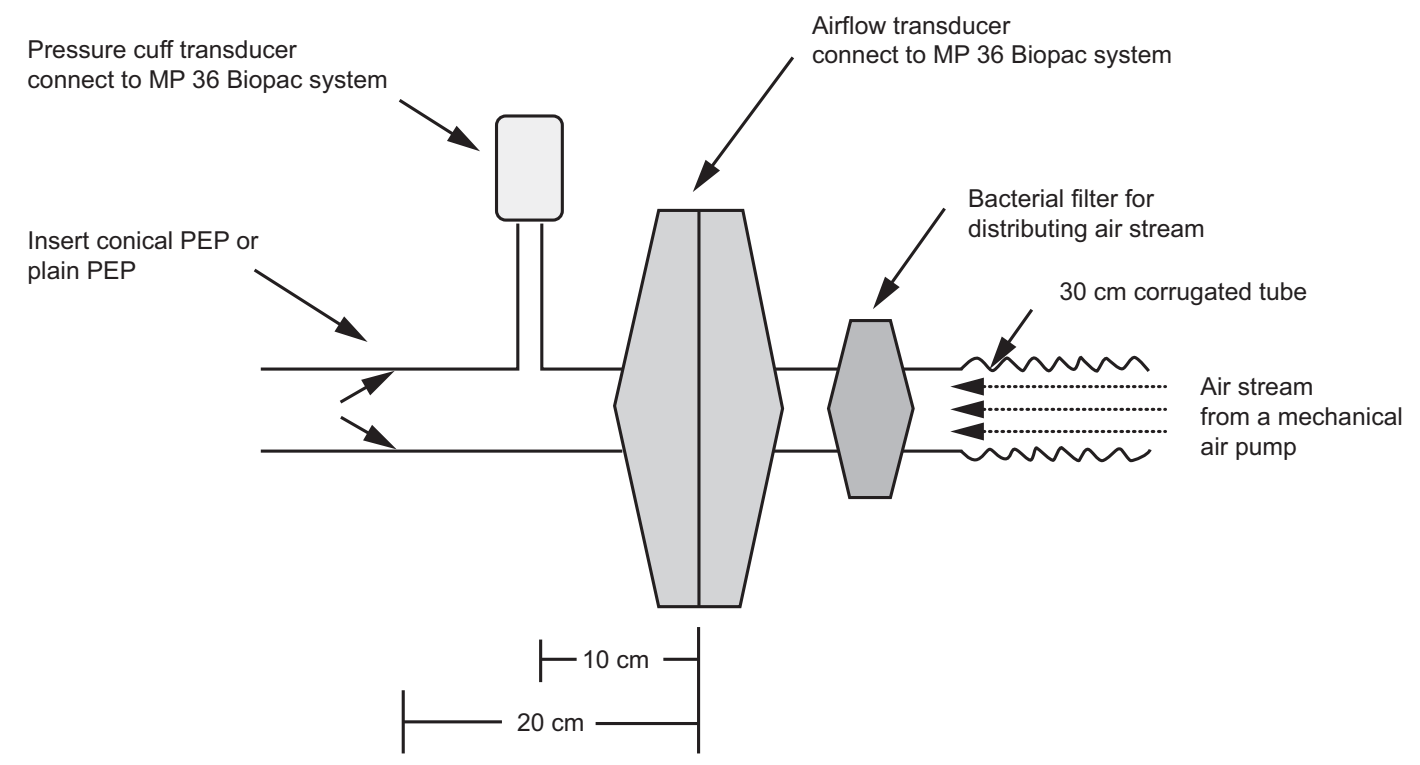

Fig. 2. Apparatus for measuring pressure and flow.

Table 1. Subjects' Characteristics

\begin{tabular}{|c|c|c|c|}
\hline Characteristic & $\begin{array}{c}\text { Experiment 2.1, } \\
\text { Young Subjects }(n=23)\end{array}$ & $\begin{array}{c}\text { Experiment 2.2, } \\
\text { Young Subjects }(n=15)^{*}\end{array}$ & $\begin{array}{c}\text { Experiment 3, } \\
\text { Older Subjects }(n=12)\end{array}$ \\
\hline Men/women, $n$ & $12 / 11$ & $10 / 5$ & $3 / 9$ \\
\hline Age, mean $\pm \mathrm{SD}$ y & $24.8 \pm 4.0$ & $24.3 \pm 3.9$ & $64.4 \pm 3.5$ \\
\hline $\mathrm{BMI}$, mean $\pm \mathrm{SD} \mathrm{kg} / \mathrm{m}^{2}$ & $22.1 \pm 2.8$ & $22.5 \pm 2.7$ & $22.2 \pm 2.8$ \\
\hline $\mathrm{IC}$, mean $\pm \mathrm{SD} \mathrm{L}$ & NA & NA & $1.85 \pm 0.36$ \\
\hline IC, mean \pm SD \%pred & NA & NA & $83.1 \pm 16.5$ \\
\hline $\mathrm{SVC}$, mean $\pm \mathrm{SD} \mathrm{L}$ & NA & NA & $2.70 \pm 0.42$ \\
\hline $\mathrm{SVC}$, mean $\pm \mathrm{SD} \%$ pred & NA & NA & $92.0 \pm 17.4$ \\
\hline $\mathrm{FEV}_{1}$, mean $\pm \mathrm{SD} \mathrm{L}$ & $3.19 \pm 0.98$ & $3.48 \pm 0.82$ & $2.06 \pm 0.38$ \\
\hline $\mathrm{FEV}_{1}$, mean $\pm \mathrm{SD} \%$ pred & $97.8 \pm 12.2$ & $98.7 \pm 11.7$ & $95.3 \pm 15.6$ \\
\hline $\mathrm{FVC}$, mean $\pm \mathrm{SD} \mathrm{L}$ & $3.62 \pm 1.03$ & $3.89 \pm 0.95$ & $2.66 \pm 0.50$ \\
\hline $\mathrm{FVC}$, mean $\pm \mathrm{SD} \%$ pred & $94.8 \pm 12.3$ & $94.9 \pm 12.4$ & $91.1 \pm 14.2$ \\
\hline $\mathrm{FEV}_{1}: \mathrm{FVC}$, mean $\pm \mathrm{SD}$ & $89.5 \pm 4.6$ & $89.6 \pm 4.6$ & $77.1 \pm 3.6$ \\
\hline $\mathrm{PEF}$, mean $\pm \mathrm{SD} \mathrm{L} / \mathrm{min}$ & $483 \pm 116$ & $515 \pm 113$ & $350 \pm 77$ \\
\hline $\mathrm{PEF}$, mean $\pm \mathrm{SD} \%$ pred & $98.1 \pm 11.8$ & $97.3 \pm 12.8$ & $73.8 \pm 16.7$ \\
\hline $\begin{array}{l}\text { * The } 15 \text { young subjects of experin } \\
\text { BMI }=\text { body mass index } \\
\text { IC }=\text { inspiratory capacity } \\
\text { NA }=\text { not applicable } \\
\% \text { pred }=\% \text { predicted } \\
\text { SVC }=\text { slow vital capacity } \\
\text { PEF }=\text { peak expiratory flow }\end{array}$ & set of the 23 subjects of experiment & & \\
\hline
\end{tabular}

\section{Experiment 2.1: Pressure-Flow Relationships During Exercise With the Conical-PEP Device}

Procedure. The subjects visited the laboratory on 3 occasions. On the first occasion, the subjects were familiarized with the procedures. On the second occasion, they undertook an incremental cycle ergometer test to determine the work load to give $60 \%$ heart rate reserve, and expiratory flow was used to select the size of the resistor for subsequent experiments. On the third occasion, the subjects exercised at a work rate to generate $60 \%$ heart rate reserve while breathing with conical-PEP device with a $1-\mathrm{cm}$ cone and a 6-mm orifice on one occasion and with a 7-mm orifice on another. The pressure and flow were measured during the breathing cycle for the last 3 breaths of the third minute of exercise when the subjects were in a steady state. A washout period between exercise tests with the 2 resistors was set for at least 2 h (Fig. 3). 




Fig. 3. Flow chart.

Incremental Exercise Test. An incremental exercise test was performed on a cycle ergometer (Corival V3, Lode B.V., Groningen, Netherland) as shown in Figure $4 \mathrm{~A}$, with the subjects breathing through a respiratory transducer unit with a nose clip. Subjects were instructed to pedal between 55 and $65 \mathrm{rpm}$, and, after an initial 3 min with no resistance, the load was increased every minute by $15 \mathrm{~W}$ for the female or $20 \mathrm{~W}$ for the male subjects until volitional fatigue or heart rate of $>80 \%$ age-related maximum heart rate.

Constant Work-Load Cycling Tests. The subjects performed 2 exercise tests at a constant load set to produce a $60 \%$ heart rate reserve. Age-related maximum heart rate was calculated as $206.9-0.69 \times$ age in years. ${ }^{16}$ After a 1-min warm up, exercise continued at the set load for $10 \mathrm{~min}$ or until volitional fatigue, ${ }^{17}$ with a $1-\mathrm{cm}$ conicalPEP device with a 6- or 7-mm orifice inserted into the respiratory transducer unit (Fig. 3B). The order of the 6and 7-mm orifice tests was randomized in a balanced de- sign. After the end of exercise, the subjects rested by sitting on the ergometer while still breathing through the respiratory transducer, although without a conical-PEP device, and recovery was followed for $10 \mathrm{~min}$.

Outcome Measures. Spirometry procedures followed American Thoracic Society/European Respiratory Society task force recommendations for standardization of lung function testing ${ }^{18}$ by using a potable spirometer (ML3500 MK8 MicroLab Desktop Spirometer, Micro Medical, Inc., Chatham Maritime, Kent, UK) for FVC maneuver. During exercise, breathing frequency, inspiratory time, expiratory time, expiratory flow, and expiratory tidal volume were recorded during the last 3 regular breaths of each minute by using a flow transducer (SS11LA, BIOPAC MP36 system). Minute ventilation was calculated from breathing frequency and tidal volume. Expiratory pressure was recorded with a pressure transducer (SS13L, BIOPAC MP36 system). The flow and pressure transducers were calibrated before each 


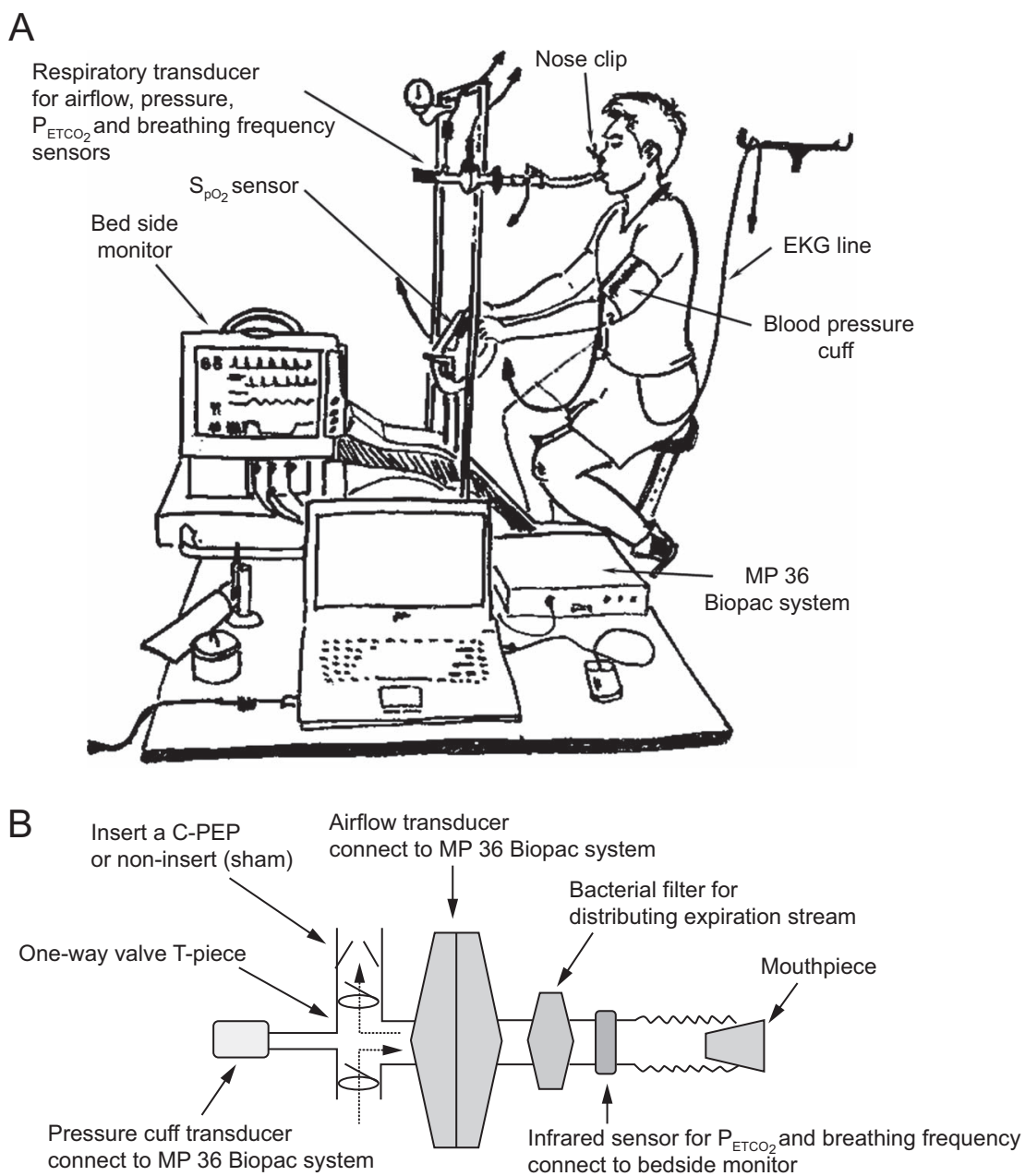

Fig. 4. Experimental apparatus setting for exercise tests. A subject on a cycle ergometer, showing the position of the respiratory transducer and associated recording equipment $(A)$; a respiratory transducer $(B)$.

exercise test. The $\mathrm{P}_{\text {ETCO }}$ and $\mathrm{S}_{\mathrm{pO}_{2}}$ were recorded with a bedside monitor (BSM 2351K, Nihon Kohden, Irvine, CA). An electrocardiogram was recorded by using the BIOPAC MP36 system to determine heart rate during exercise. Ratings of perceived breathlessness were assessed every 2 min by using a modified Borg scale $(0-10)$. Oscillometric blood pressure was measured at rest and immediately after exercise by using the bedside monitor with an arm cuff and bedside monitor. In addition, during the recovery phase, the subjects were asked about any adverse symptoms during exercise, including dizziness, tinnitus, or chest tightness.

\section{Experiment 2.2: Cardiopulmonary Responses During Exercise With the Conical-PEP Device}

Procedure. Fifteen of the 23 subjects from experiment 2.1 undertook 2 constant work load tests, one breathing with a conical-PEP device, the other with the sham device. The conical-PEP and sham tests were randomly allocated in a balanced design, and a washout period of at least $2 \mathrm{~h}$ was allowed between the constant load tests (Fig. 4). Cardiopulmonary parameters were collected at rest, during exercise, and immediately after exercise (similar to experiment 2.1). After the incremental exercise test, a suitable resistor was selected to be used during the following constant load test. The size of the conical-PEP resistor was selected for each subject based on the ventilation at the end of exercise and peak expiratory flow measurements. Based on the results of experiments 1 and 2.1, those subjects with an expiratory flow of $1 \mathrm{~L} / \mathrm{s}$ or more, and a peak flow of $400 \mathrm{~mL} / \mathrm{s}$ or more, were allocated a resistor with a $7-\mathrm{mm}$ orifice to minimize the pressure at higher flows, whereas other subjects were given a 6-mm orifice with the aim of maintaining the pressure at the lower flows. The subjects were then invited to try breathing with the selected 
resistor with deep and rapid breaths as they might do during exercise to become familiar with the sensation of breathing with the device. The constant work load tests were similar to experiment 2.1 but had 2 conditions: one, breathing with a suitable conical-PEP device; and one, of breathing without a conical-PEP device (sham). All outcomes measurements were similar to experiment 2.1.

\section{Experiment 3: Cardiopulmonary Responses During Exercise With a Conical-PEP Device in the Older Subjects}

Subjects and Study Design. Twelve healthy older subjects ( 3 men) were recruited from the local community, all had normal lung function (Table 1) and no contraindications for moderate exercise. The study design was a crossover design similar to experiment 2.2.

\section{Procedure and Outcome Measurements}

Pulmonary function was measured at rest and at the end of exercise by using a Pneumotach KOKO spirometer (Hallam, PA) by following the American Thoracic Society/European Respiratory Society task force recommendations for standardization of lung function testing ${ }^{18}$ and for FVC, inspiratory capacity, and slow vital capacity measurement. Inspiratory capacity and slow vital capacity were measured at rest and immediately after exercise. The volume transducer was calibrated before each exercise test. Predictive spirometry values used were those of Morris. ${ }^{19}$ Other outcome measures were the same as for the young subjects, described above (Experiment 2.2).

\section{Data Analysis}

The pressure-flow curves were obtained by fitting a trend line with the general formula $\mathrm{P}=K \times u^{2} / d^{2}$ by using a nonlinear least squares regression, where $\mathrm{P}$ is the pressure in $\mathrm{cm} \mathrm{H}_{2} \mathrm{O}, u$ is flow in $\mathrm{L} / \mathrm{s}$, and $d$ is the diameter of the resistor orifice in $\mathrm{cm}$, with $K$ being a constant. Descriptive statistics (mean $\pm \mathrm{SD}$ ) were used to report subject characteristics and cardiopulmonary responses to interventions. The Shapiro-Wilk test was used to test data distribution for normality. Two-way repeated measure analysis of variance with post hoc paired $t$ tests and Bonferroni correction were used to determine the significance of differences between time and conditions. The Wilcoxon signed-rank test was used to determine the significance of differences of rate of perceived breathlessness within and between conditions. SPSS version 17.0 (SPSS, Chicago, Illinois) was used for all analysis. Significance was accepted at $P<.05$.

\section{Results}

\section{Experiment 1: Bench Testing of the Pressure-Flow Relationships of Different Resistors}

The Effect of Orifice Diameter. The pressure generated for a range of flows when using resisters with plain orifices (no cone) of 5-, 6-, and 7-mm diameter are shown in Figure 5A. With no resistor in place, no pressure was recorded with air flows from 0.1 to $0.7 \mathrm{~L} / \mathrm{s}$; but, at higher flows, there was a slight increase, to $0.6 \mathrm{~cm} \mathrm{H}_{2} \mathrm{O}$ at flow $1.1 \mathrm{~L} / \mathrm{s}$ and to $1.0 \mathrm{~cm} \mathrm{H}_{2} \mathrm{O}$ at a flow $1.5 \mathrm{~L} / \mathrm{s}$. With a $5 \mathrm{~mm}$ orifice, the pressure at a low flow of $0.5 \mathrm{~L} / \mathrm{s}$, was $11.0 \pm 0.3 \mathrm{~cm} \mathrm{H}_{2} \mathrm{O}$ within the clinically useful range, but the pressure increased rapidly, with increasing flow that reached very high pressures, of $58.1 \pm 1.7 \mathrm{~cm} \mathrm{H}_{2} \mathrm{O}$ at flows of $\sim 1 \mathrm{~L} / \mathrm{s}(60 \mathrm{~L} / \mathrm{min})$, which might be experienced during mild-to-moderate exercise. Increasing the diameter of the orifice to 6 and $7 \mathrm{~mm}$ reduced the pressure at a flow of $0.5 \mathrm{~L} / \mathrm{s}$ to $5.2 \pm 0.2 \mathrm{~cm} \mathrm{H}_{2} \mathrm{O}$ and $3.6 \pm 0.1 \mathrm{~cm} \mathrm{H}_{2} \mathrm{O}$, and to $23.2 \pm 0.2 \mathrm{~cm} \mathrm{H}_{2} \mathrm{O}$ and $15.3 \pm 0.3 \mathrm{~cm} \mathrm{H}_{2} \mathrm{O}$ at a flow of $1 \mathrm{~L} / \mathrm{s}$, respectively. Orifices of 5,6 , and $7 \mathrm{~mm}$ produced $20 \mathrm{~cm} \mathrm{H}_{2} \mathrm{O}$, probably the maximum useful pressure, at 0.6 , 0.9 , and $1.1 \mathrm{~L} / \mathrm{s}$, respectively.

The Effect of the Resistor Shape. Changing the shape of the resistor from a plain hole to a $1-\mathrm{cm}$ cone with a similar orifice diameter reduced the pressures generated at all flows (Fig. 6B). At a flow of $1 \mathrm{~L} / \mathrm{s}$, the pressures were $44.1 \pm 1.0,18.0 \pm 0.3$, and $12.1 \pm 0.3 \mathrm{~cm} \mathrm{H}_{2} \mathrm{O}$ for orifices $5,6,7 \mathrm{~mm}$, respectively, a reduction of $18-26 \%$ compared with the plain orifice (compare Fig. 5A and Fig. 5B) and generated pressures of $20 \mathrm{~cm} \mathrm{H}_{2} \mathrm{O}$ at flows of 0.7 , 1.1 , and $1.3 \mathrm{~L} / \mathrm{s}$, for the three orifices, which were higher than for similar orifice of a plain shape (compare Fig. 5A and Fig. 5B). It was found that the longer the cone, the lower the pressure generated for a given size of orifice and flow (Fig. 6C). With a 4-cm cone and an orifice of $5 \mathrm{~mm}$, the pressure generated at a flow of $0.5 \mathrm{~L} / \mathrm{s}$ was $6.2 \pm 0.3 \mathrm{~cm} \mathrm{H}_{2} \mathrm{O}$, whereas, at $1 \mathrm{~L} / \mathrm{s}$, the pressure was $25.7 \pm 1.5 \mathrm{~cm} \mathrm{H}_{2} \mathrm{O}$; both pressures were probably in the clinically useful range.

\section{Experiment 2: Pressure-Flow Relationships and Cardiopulmonary Responses During Exercise With the Conical-PEP Device in the Young Subjects}

Young subjects were healthy and had normal lung functions (Table 1). None had cardiovascular, neuromuscular, or musculoskeletal symptoms.

Pressure-Flow Relationships During Exercise With the Conical-PEP Device in the Young Subjects. The pressure-flow relationships seen in the bench tests were largely replicated with the subjects exercising at moderate work 

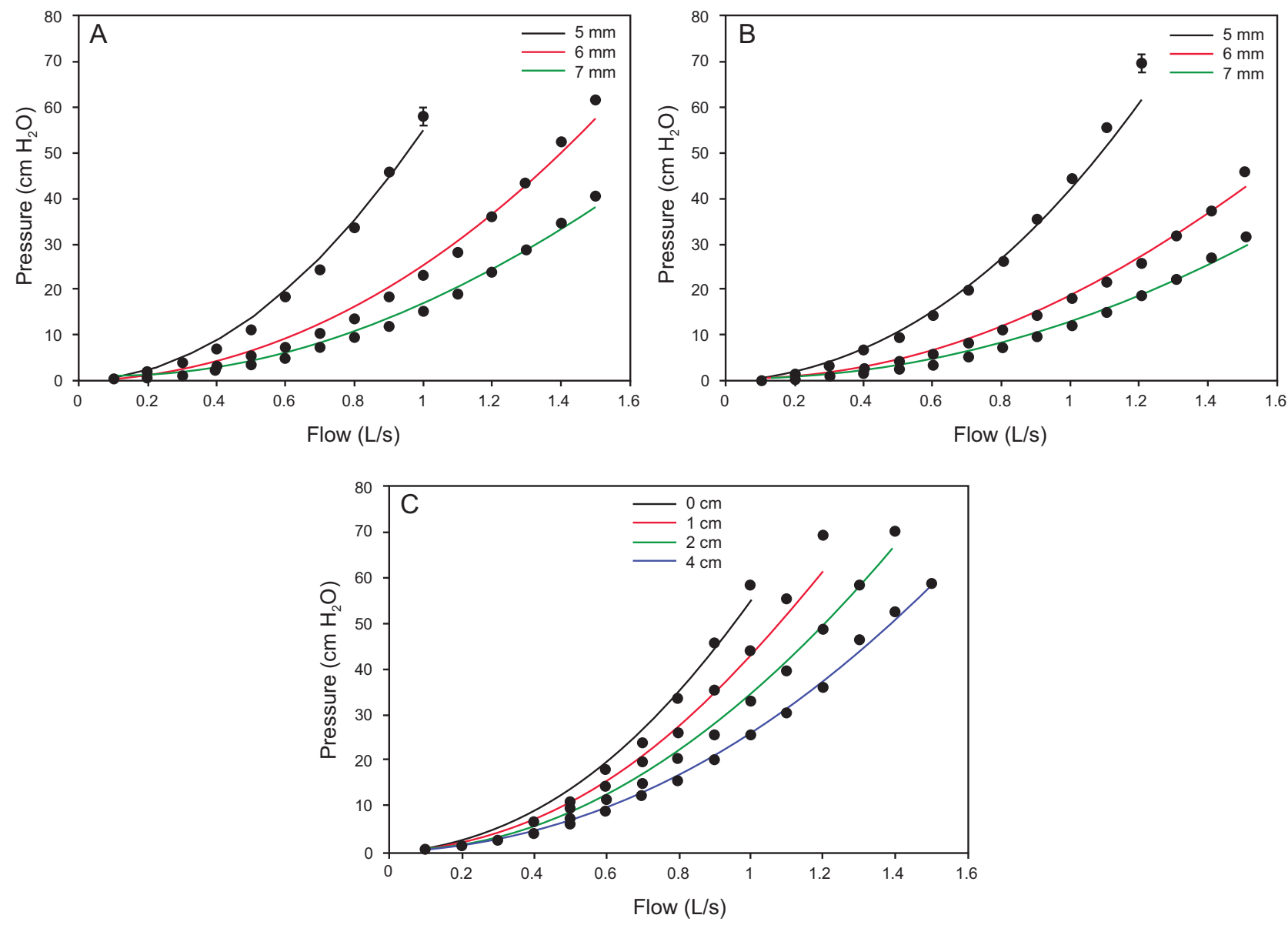

Fig. 5. Pressure-flow characteristics of different resistors. A plain orifice with no cone (A); the effect of varying orifice diameters with a 1-cm cone (B); and the effect of varying cone lengths with a fixed 5-mm-diameter orifice (C). Data points are the mean of 3 measurements for each resistor.

rates. Data are shown in Figure 6A and Figure 6B for one subject, with a relatively low peak expiratory flow of $\sim 0.8 \mathrm{~L} / \mathrm{s}$ exercising on 2 occasions, once with the conicalPEP device, $1 \mathrm{~cm}$ in length with a 6-mm orifice (Fig. 6A), with the peak pressure of $\sim 9 \mathrm{~cm} \mathrm{H}_{2} \mathrm{O}$, and, on the second occasion, with a 7-mm orifice (Fig. 6B), the peak pressure was $\sim 6 \mathrm{~cm} \mathrm{H}_{2} \mathrm{O}$. These pressures were very similar to those predicted by the bench testing, as indicated by the solid lines, in Fig 6. Another subject with higher peak flows, of up to $1.4 \mathrm{~L} / \mathrm{s}$, is shown in Figure $6 \mathrm{C}$ and Figure 6D. With a 6-mm orifice (Fig. 6C), the peak pressure was $\sim 20 \mathrm{~cm} \mathrm{H}{ }_{2} \mathrm{O}$, and, with the 7-mm orifice (Fig. 6D), the peak pressure was lower, at $15 \mathrm{~cm} \mathrm{H}_{2} \mathrm{O}$.

Cardiopulmonary Responses During Exercise With the Conical-PEP Device in the Young Subjects. Young subjects exercised at a constant work load set at $60 \%$ heart rate reserve while breathing with a $1-\mathrm{cm}$ conical-PEP device and orifice of either 6- or 7-mm diameter. The size of orifice was selected according to the subject's peak flow during exercise (see the methods section). Nine subjects exercised with a 6-mm conical-PEP device; the remaining
6 subjects used a 7-mm conical-PEP device. The data were compared with the same subject exercising with no PEP device (sham).

Heart rate responses were identical when using the sham device or the conical-PEP device, and all reached a steady state by $3 \mathrm{~min}$ when the pressure-flow measurements were made. The mean \pm SD peak pressure during exercise with conical-PEP breathing at steady state (third minute) was $11.4 \pm 4.5 \mathrm{~cm} \mathrm{H}_{2} \mathrm{O}$, with an mean $\pm \mathrm{SD}$ expiratory flow of $1.19 \pm 0.31 \mathrm{~L} / \mathrm{s}$. The exercise times were no difference $(5.6 \pm 2.3 \mathrm{~min}$ for the sham and $5.7 \pm 2.0 \mathrm{~min}$ for conicalPEP device). At the end of the exercise, the subjects reported no differences in their perceptions of breathlessness, when using a modified Borg score, while breathing with the sham (median 5 [interquartile range 4-5]) or the conical-PEP device (median 6 [interquartile range, 5-6]) (Table 2). There were no differences in breathing frequency, expiratory tidal volume, breathing frequency, and minute ventilation between sham and conical-PEP breathing at any time during the exercise. However, at the end of exercise, when using the conical-PEP device, the expiratory time to breathing cycle time ratio (expiratory time to 

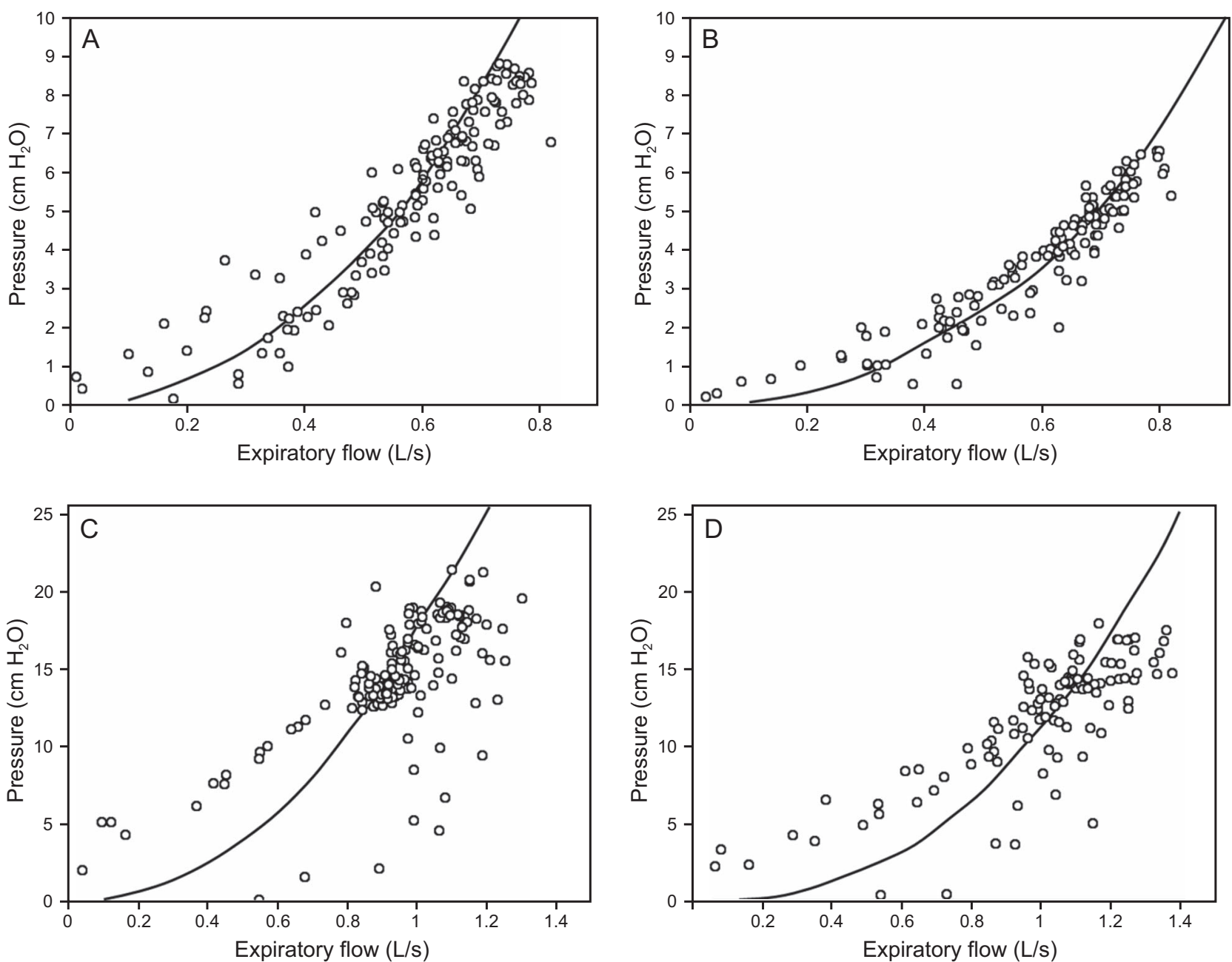

Fig. 6. Pressure-flow relationships during exercise with conical-positive expiratory pressure (PEP) breathing. A and B: A female subject (age, $27 \mathrm{y}$; body mass index [BMI], $19.1 \mathrm{~kg} / \mathrm{m}^{2} ; \mathrm{FEV}_{1}, 2.43 \mathrm{~L}$ [90\% predicted]; peak expiratory flow [PEF], $7.17 \mathrm{~L} / \mathrm{s}$ [110\% predicted]), with a peak exercise flow of $0.8 \mathrm{~L} / \mathrm{s}$ breathing and with a 1-cm-long conical-PEP device with an orifice of 6-mm (A) or 7-mm (B) diameter. C and D: A male subject (age, 22 y; BMl, $24.9 \mathrm{~kg} / \mathrm{m}^{2}$; $\mathrm{FEV}_{1}, 3.87 \mathrm{~L}$ [88\% predicted]; PEF, $9.80 \mathrm{~L} / \mathrm{s}$ [89\% predicted]), with a peak exercise flow of 1.4 $\mathrm{L} / \mathrm{s}$ breathing with a $1-\mathrm{cm}$-long conical-PEP device with a 6-mm (C) or 7-mm (D) diameter orifice. Data points were recorded every $0.032 \mathrm{~s}$ during 3 breaths while exercising in a steady state (60\% heart rate reserve).

breathing cycle time ratio) was maintained, whereas it was significantly reduced when using the sham device compared with resting (Table 2). The $\mathrm{S}_{\mathrm{pO}_{2}}$ tended to be slightly lower with conical PEP and the $\mathrm{P}_{\mathrm{ETCO}}$, was a little higher, but there were no statistically significant differences between conical PEP and sham in these measures at any time. In the absence of any adverse reactions to exercise with a conical-PEP device, it was considered acceptable for the exercise tests to be repeated with the older subjects.

\section{Experiment 3: Cardiopulmonary Responses During Exercise With a Conical-PEP Device in Older Subjects}

The older subjects were healthy, with normal lung function (Table 1) and no cardiovascular, neuromuscu- lar, or musculoskeletal conditions. The older subjects reached a steady state, as indicated by heart rate (Fig. 7), by 4-5 min and exercised, on average, at $60 \%$ heart rate reserve or $\sim 75 \%$ estimated maximum heart rate (Table 3), although there was variation among the subjects. Heart rates were the same for conical PEP and sham at all times during the exercise and subsequent recovery. Some subjects stopped before $10 \mathrm{~min}$ due to dyspnea in both conical-PEP $(n=5)$ and sham $(n=4)$ conditions.

The cardiopulmonary responses during exercise were the same in the conical-PEP and sham conditions but the mean $\left(6.6 \mathrm{~cm} \mathrm{H}_{2} \mathrm{O}\right)$ and peak expiratory $\left(10.4 \mathrm{~cm} \mathrm{H}_{2} \mathrm{O}\right)$ pressures were significantly higher in conical-PEP breathing (Table 3), which confirmed that the conical-PEP device 
Table 2. Cardiopulmonary Responses at Rest and the End of Exercise in the Young Subjects

\begin{tabular}{|c|c|c|c|c|}
\hline \multirow{2}{*}{ Parameters } & \multicolumn{2}{|c|}{ At Rest } & \multicolumn{2}{|c|}{ At End of Exercise } \\
\hline & C-PEP & Sham & C-PEP & Sham \\
\hline Heart rate, mean $\pm \mathrm{SD}$ beats $/ \mathrm{min}$ & $77.3 \pm 6.6$ & $77.0 \pm 7.9$ & $142.9 \pm 2.9^{*}$ & $143.1 \pm 2.6^{*}$ \\
\hline $\mathrm{MAP}$, mean $\pm \mathrm{SD} \mathrm{mm} \mathrm{Hg}$ & $87.7 \pm 6.4$ & $82.9 \pm 8.9$ & $100.9 \pm 12.3^{*}$ & $95.7 \pm 13.7 *$ \\
\hline Frequency, mean $\pm \mathrm{SD}$ breaths $/ \mathrm{min}$ & $12 \pm 5$ & $12 \pm 5$ & $21 \pm 7 *$ & $21 \pm 6^{*}$ \\
\hline $\mathrm{T}_{\mathrm{E}}: \mathrm{T}_{\text {total }}$, mean $\pm \mathrm{SD}$ & $0.62 \pm 0.10$ & $0.62 \pm 0.10$ & $0.59 \pm 0.05$ & $0.54 \pm 0.07 *$ \\
\hline Tidal volume, mean $\pm \mathrm{SD}$ L & $0.96 \pm 0.46$ & $1.00 \pm 0.61$ & $1.60 \pm 0.56^{*}$ & $1.74 \pm 0.66^{*}$ \\
\hline Minute ventilation, mean $\pm \mathrm{SD} L$ & $11.13 \pm 4.03$ & $13.45 \pm 9.74$ & $32.72 \pm 7.70 *$ & $35.78 \pm 10.55^{*}$ \\
\hline $\mathrm{P}_{\mathrm{ETCO}_{2}}$, mean $\pm \mathrm{SD} \mathrm{mm} \mathrm{Hg}$ & $35 \pm 6$ & $34 \pm 6$ & $50 \pm 7 *$ & $47 \pm 9 *$ \\
\hline $\mathrm{S}_{\mathrm{pO}_{2}}$, mean $\pm \mathrm{SD} \%$ & $98 \pm 1$ & $99 \pm 1$ & $96 \pm 2 *$ & $97 \pm 2 *$ \\
\hline Borg RPB score, median (IQR) & $0(0-0)$ & $0(0-0)$ & $6(5-6) \dagger$ & $5(4-6) \dagger$ \\
\hline $\begin{array}{l}\text { * Significant within condition (resting vs end ex } \\
\dagger \text { Significant within condition (resting vs end ex } \\
\mathrm{C}-\mathrm{PEP}=\text { Conical positive expiratory pressure de } \\
\mathrm{MAP}=\text { mean arterial pressure } \\
\mathrm{T}_{\mathrm{E}}=\text { expiratory time } \\
\mathrm{T}_{\text {total }} \text { = breathing cycle time } \\
\mathrm{P}_{\mathrm{ETCO}} \text { = partial pressure of end-tidal carbon di } \\
\mathrm{RPB}=\text { rate of perceived breathlessness } \\
\mathrm{IQR}=\text { interquartile range }\end{array}$ & $\begin{array}{l}-.030 \text {, by using the } \\
\text { by using the Wilco }\end{array}$ & test & & \\
\hline
\end{tabular}

generated positive expiratory pressures in the therapeutic range. Inspiratory capacity and slow vital capacity both decreased at the end of the exercise but not sufficiently to signify significant dynamic hyperinflation and with no differences between the conical-PEP and sham conditions (Table 3).

Flow-volume loops for 2 older subjects are shown in Figure 8. The loops were of similar shape during con-
ical-PEP and sham breathing, both at rest and during exercise, and with no indication of flow limitation. Flows were similar in the 2 conditions, but volumes were larger during exercise with conical PEP. It is notable that, when breathing with conical PEP, the volume increased earlier during exercise than in the sham condition.

There were no adverse effects of breathing with the conical-PEP device; $\mathrm{S}_{\mathrm{pO}_{2}}$ and $\mathrm{P}_{\mathrm{ETCO}}$ showed similar pat-

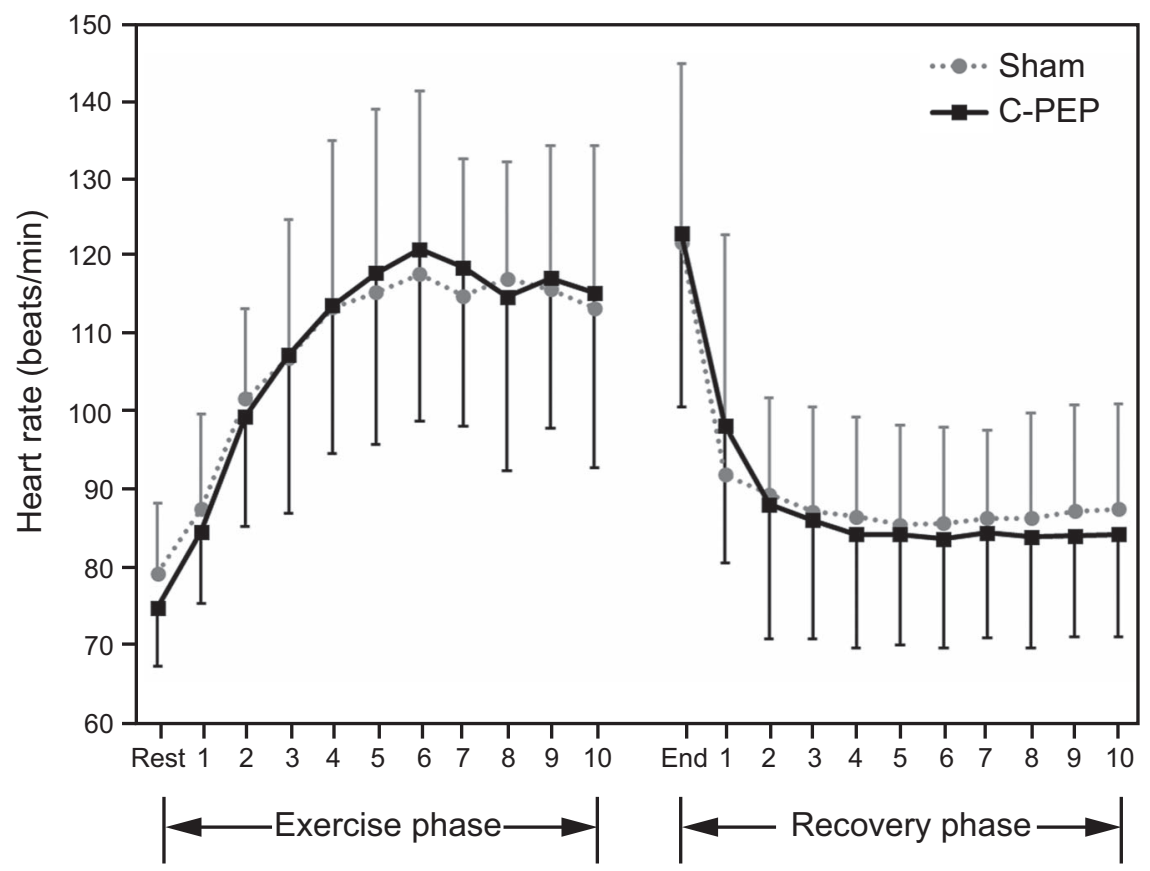

Fig. 7. Mean \pm SD of heart rate during constant load exercise and recovery in the older subjects. C-PEP = conical positive expiratory pressure. 
Table 3. Cardiopulmonary Responses at Rest and the End of Exercise in Older Subjects

\begin{tabular}{|c|c|c|c|c|}
\hline \multirow{2}{*}{ Parameters } & \multicolumn{2}{|c|}{ At Rest } & \multicolumn{2}{|c|}{ At End of Exercise } \\
\hline & C-PEP & Sham & C-PEP & Sham \\
\hline Heart rate, mean $\pm \mathrm{SD}$ beats $/ \mathrm{min}$ & $75.1 \pm 7.9$ & $79.5 \pm 9.4$ & $123.1 \pm 23.3^{*}$ & $122.0 \pm 24.0 *$ \\
\hline $\mathrm{MAP}$, mean $\pm \mathrm{SD} \mathrm{mm} \mathrm{Hg}$ & $90.5 \pm 7.8$ & $90.8 \pm 11.7$ & $104.5 \pm 10.7 *$ & $112.3 \pm 14.5^{*}$ \\
\hline Frequency, mean $\pm \mathrm{SD}$ breaths/min & $17 \pm 4$ & $17 \pm 4$ & $27 \pm 7 *$ & $26 \pm 5^{*}$ \\
\hline $\mathrm{T}_{\mathrm{E}}: \mathrm{T}_{\text {total }}$, mean $\pm \mathrm{SD}$ & $0.57 \pm 0.05$ & $0.57 \pm 0.04$ & $0.55 \pm 0.05$ & $0.54 \pm 0.06$ \\
\hline Tidal volume, mean $\pm \mathrm{SD} \mathrm{L}$ & $0.46 \pm 0.14$ & $0.47 \pm 0.16$ & $0.84 \pm 0.28^{*}$ & $0.76 \pm 0.30 *$ \\
\hline Minute ventilation, mean $\pm \mathrm{SD} L$ & $7.96 \pm 2.73$ & $8.19 \pm 2.34$ & $20.09 \pm 7.07 *$ & $19.06 \pm 9.05^{*}$ \\
\hline $\mathrm{P}_{\mathrm{ETCO}_{2}}$, mean $\pm \mathrm{SD} \mathrm{mm} \mathrm{Hg}$ & $43 \pm 4$ & $42 \pm 3$ & $50 \pm 6^{*}$ & $47 \pm 5^{*}$ \\
\hline $\mathrm{S}_{\mathrm{pO}_{2}}$, mean $\pm \mathrm{SD} \%$ & $98 \pm 1$ & $98 \pm 1$ & $97 \pm 2^{*}$ & $97 \pm 1^{*}$ \\
\hline Expiratory flow, mean $\pm \mathrm{SD} \mathrm{L} / \mathrm{s}$ & $0.27 \pm 0.1$ & $0.28 \pm 0.11$ & $0.61 \pm 0.21^{*}$ & $0.61 \pm 0.32 *$ \\
\hline Peak expiratory flow, mean $\pm \mathrm{SD} \mathrm{L} / \mathrm{s}$ & $0.38 \pm 0.13$ & $0.36 \pm 0.12$ & $0.91 \pm 0.34^{*}$ & $0.91 \pm 0.40^{*}$ \\
\hline Expiratory pressure, mean $\pm \mathrm{SD} \mathrm{cm} \mathrm{H}_{2} \mathrm{O}$ & $1.20 \pm 0.72$ & $1.03 \pm 0.40$ & $6.64 \pm 3.54^{*} \dagger$ & $2.72 \pm 1.77 *$ \\
\hline Peak expiratory pressure, mean $\pm \mathrm{SD} \mathrm{cm} \mathrm{H}_{2} \mathrm{O}$ & $1.95 \pm 0.79$ & $1.65 \pm 0.67$ & $10.42 \pm 5.52 * \dagger$ & $4.09 \pm 2.54^{*}$ \\
\hline $\mathrm{IC}$, mean $\pm \mathrm{SD} \mathrm{L}$ & $1.83 \pm 0.41$ & $1.87 \pm 0.49$ & $1.67 \pm 0.40^{*}$ & $1.73 \pm 0.36^{*}$ \\
\hline $\mathrm{SVC}$, mean $\pm \mathrm{SD} \mathrm{L}$ & $2.70 \pm 0.50$ & $2.71 \pm 0.50$ & $2.60 \pm 0.52$ & $2.36 \pm 0.61 *$ \\
\hline Borg RPB score, median (IQR) & $0(0-0)$ & $0(0-0)$ & $3.5(3-4.5) \ddagger$ & $3.5(3-5) \ddagger$ \\
\hline $\begin{array}{l}\text { * Significant within condition (resting vs end exercise), } P=.00 \\
\dagger \text { Significant differences between conditions, } P=.020-.040 \text { at } \\
\text { † Significant within condition (resting vs end exercise), } P=.03 \\
\text { C-PEP = conical positive expiratory pressure } \\
\text { MAP = mean arterial pressure } \\
\mathrm{T}_{\mathrm{E}}=\text { expiratory time } \\
\mathrm{T}_{\text {total }}=\text { breathing cycle time } \\
\mathrm{P}_{\mathrm{ETCO}}=\text { = partial pressure of end-tidal carbon dioxide } \\
\text { IC }=\text { inspiratory capacity } \\
\text { SVC = slow vital capacity } \\
\text { RPB = rate of perceived breathlessness } \\
\text { IQR = interquartile range }\end{array}$ & $\begin{array}{l}\text { ing the paired } t \text { te } \\
\text { ercise, by using th } \\
\text { te Wilcoxon signe }\end{array}$ & & & \\
\hline
\end{tabular}

terns of response to exercise and recovery, whereas the increase in mean arterial blood pressure was significantly less in the conical-PEP condition (Table 2, Fig. 9A, Fig. 9B, and Fig. 9C). The subjects found breathing with the conical-PEP device during exercise to be acceptable, with the ratings of perceived breathlessness the same as in the sham condition during exercise and recovery (Fig. 9D). No adverse symptoms were reported during exercise with the conical-PEP device.

\section{Discussion}

The 4 major findings were that (1) a plain 5-mm orifice may not be suitable to use during exercise but $6-7 \mathrm{~mm}$ orifices could be used with flows $<1 \mathrm{~L} / \mathrm{s}$ during mild exercise that generated pressure $\sim 20 \mathrm{~cm} \mathrm{H}_{2} \mathrm{O}$; (2) the changing shape of the PEP device to a cone reduced the pressure generated for a given orifice and flow compared with a plain orifice, which extended the useful range beyond $1 \mathrm{~L} / \mathrm{s}$ when using an orifice of 6 or $7 \mathrm{~mm}$, into the range of mild-moderate exercise; (3) PEP generated by the conical-PEP device during exercise was related to flow in a similar way to that found in the bench test; and (4) the conical-PEP device, when gen- erating pressures of $\sim 11 \mathrm{~cm} \mathrm{H}_{2} \mathrm{O}$ during exercise, was found to be acceptable, with no adverse effects in the young and older subjects.

The pressure developed for a given flow through a PEP device such as used here depends on a number of factors: tube and orifice diameter, tube length, and the shape of the resistor. The pressures we reported here were primarily generated by the resistor, although the length of tubing before the resistor (Fig. 2) may have contributed a pressure of up to $1 \mathrm{~cm} \mathrm{H}_{2} \mathrm{O}$ at the highest flows, consistent with the observations of Mestriner et al. ${ }^{6}$ The important factor that determined pressure was the size of the orifice, and, as is shown in Figure 4A, the pressure was related to the square of the flow and inversely to the square of the orifice diameter in much the same way as described by Fagevik Olsén et al, ${ }^{20}$ although that study was concerned with relatively small orifices ( 1.5 to $5 \mathrm{~mm}$ diameter) and very low flows $(0.17-0.30 \mathrm{~L} / \mathrm{s})$. The pressure-flow relationship was also influenced by incorporating the resistor into a cone shape, which reduced the pressure for a given flow, with the reduction being proportional to the length of the cone (Fig. 5B and Fig. 5C). Consequently, both the size of the orifice and the length of the cone can be adjusted to provide suitable pressures but also to match the physical 

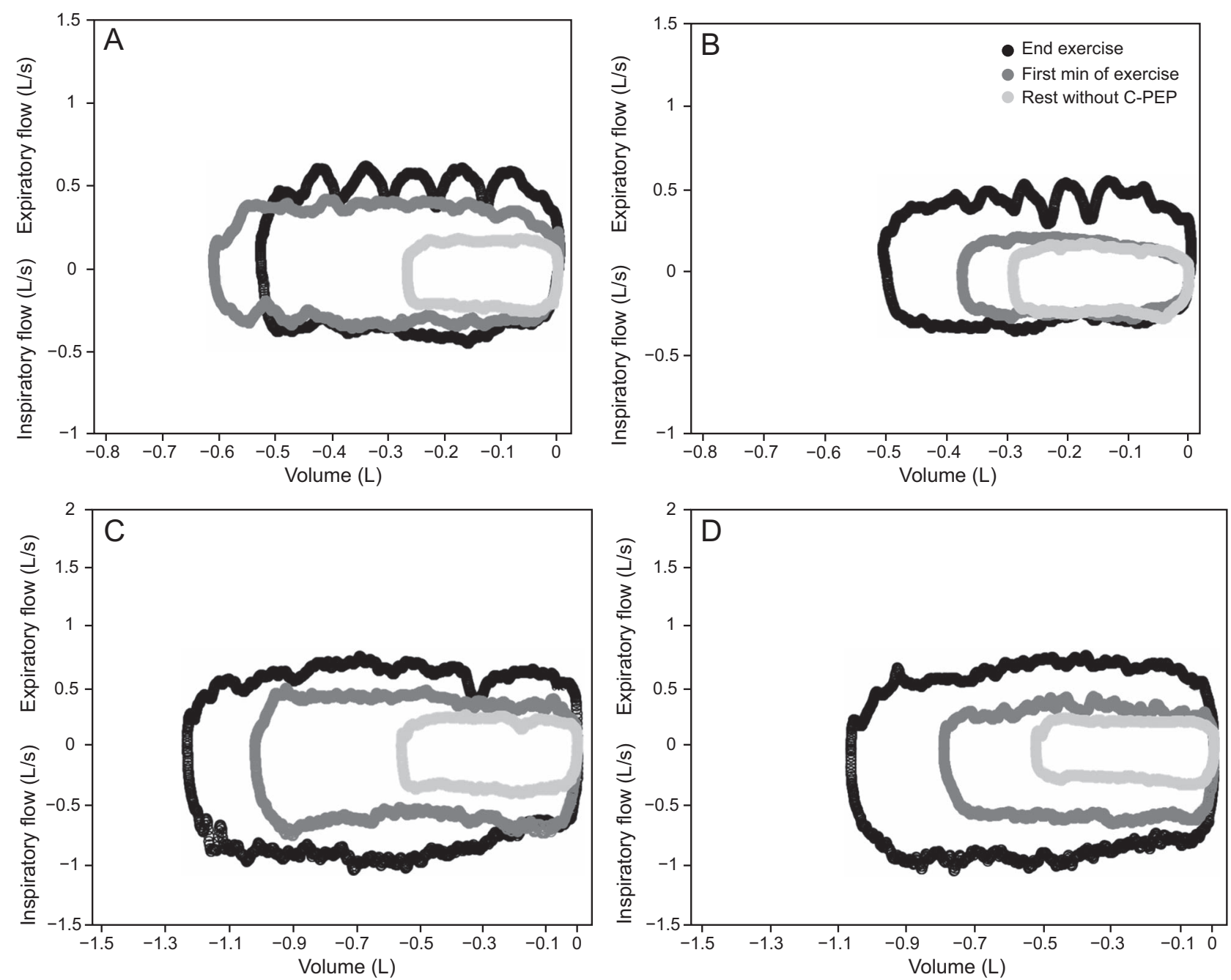

Fig. 8. Individual flow-volume curves at rest without conical positive expiratory pressure (PEP), the first min of exercise, and the end of exercise. A female subject (age, 72 y; body mass index [BMl], $22.3 \mathrm{~kg} / \mathrm{m}^{2} ; \mathrm{FEV}_{1}, 1.88 \mathrm{~L}$ [101\% predicted]; peak expiratory flow [PEF], $4.31 \mathrm{~L} / \mathrm{s}[77 \%$ predicted]), with an exercise flow of $0.5 \mathrm{~L} / \mathrm{s}$ breathing with a 1-cm-long conical-PEP device with an orifice of $6 \mathrm{~mm}$ (A) and sham (B). A male subject (age, $67 \mathrm{y}$; BMI, $21.9 \mathrm{~kg} / \mathrm{m}^{2} ; \mathrm{FEV}_{1}, 2.30 \mathrm{~L}$ [90\% predicted]; PEF, $6.84 \mathrm{~L} / \mathrm{s}$ [82\% predicted]), with an exercise flow of $0.7 \mathrm{~L} / \mathrm{s}$ breathing with a 1-cm-long conical-PEP device with an orifice of $7 \mathrm{~mm}$ (C) and sham (D).

requirements, for instance, if the resistor is to be fitted into a mask or other breathing aid.

Most flow-dependent PEP devices have been used in postsurgical rehabilitation, where expiratory flows are low, and, in a recent evaluation of PEP devices, Fagevik Olsén et $\mathrm{al}^{20}$ tested a range of resistors with holes of 2,3 , and $4 \mathrm{~mm}$, which, at flows of 10 and $18 \mathrm{~L} / \mathrm{min}$, gave clinically useful pressures. However, resistors of this size would give impossibly high pressures at flows encountered during exercise, even with patients with COPD. These investigators also commented that there was very little consistency because resistors with apparently similar size holes give different pressures in different devices. ${ }^{20}$ We took $20 \mathrm{~cm} \mathrm{H}_{2} \mathrm{O}$ to be the upper limit for use during exercise, partly because this was approximately the maximum that can be tolerated but also because PEP of $5-20 \mathrm{~cm} \mathrm{H}_{2} \mathrm{O}$ is commonly used in physiotherapy. ${ }^{21}$ A PEP of $10-20 \mathrm{~cm}$ $\mathrm{H}_{2} \mathrm{O}$ for airway clearance has been suggested in the AARC clinical practice guideline. ${ }^{22}$ Low PEEP, at 5 and $10 \mathrm{~cm}$ $\mathrm{H}_{2} \mathrm{O}$, has also been reported to be sufficient to improve lung mechanics and reduce the work of breathing by lowering the inspiratory threshold in COPD without increased hyperinflation. ${ }^{23-25}$

PEP loads of 5-10 $\mathrm{cm} \mathrm{H}_{2} \mathrm{O}$ in a threshold-PEP device have been reported to reduce dynamic hyperinflation ${ }^{7}$ and improve the 6-min walk distance, ${ }^{11}$ and Fagevik Olsén et $\mathrm{a}^{26}$ suggested the use of $5-10 \mathrm{~cm} \mathrm{H}_{2} \mathrm{O}$ to reduce hyperinflation. Peak positive pressures of $4-20 \mathrm{~cm} \mathrm{H}_{2} \mathrm{O}$ with flow-dependent PEP devices have also been shown to reduce dynamic hyperinflation. ${ }^{13,15}$ It, therefore, is evident that PEP in the range of $5-20 \mathrm{~cm} \mathrm{H}_{2} \mathrm{O}$ is suitable for reducing hyperinflation, but the difficulty with 

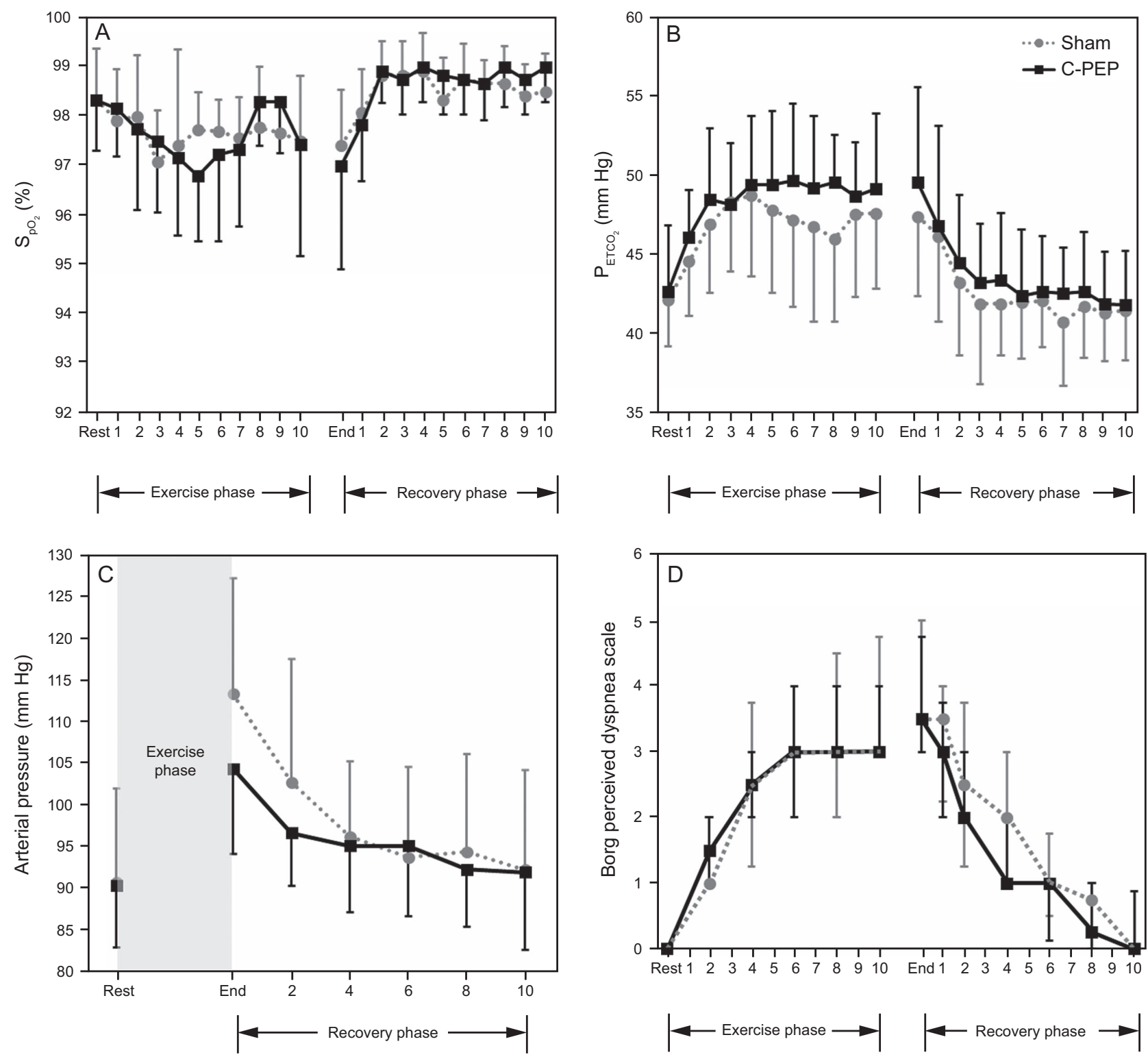

Fig. 9. Cardiopulmonary changes during exercise and recovery in older subjects. Data are mean $\pm S D(A, B, C)$ and median (interquartile range $[I Q R])(D) . S_{\mathrm{pO}_{2}}(A) ; P_{E T C O}(B)$; mean arterial pressure (C); rating of perceived breathlessness (D). C-PEP $=$ conical positive expiratory pressure.

flow-dependent devices is that a resistor that provides a suitable pressure during quiet breathing at rest offers too great a resistance at the higher flows encountered during exercise.

There is probably no perfect design, but we found that a 1-cm cone with an orifice of 6 or $7 \mathrm{~mm}$ provided pressures of between 5 and $20 \mathrm{~cm} \mathrm{H}_{2} \mathrm{O}$ over the range of flows that span rest-to-moderate exercise (Fig. 5B). The smaller 6-mm orifice was suitable for a subject with a relatively low $\mathrm{FEV}_{1}$ and peak expiratory flow (Fig. 6A), whereas, for a subject with a higher $\mathrm{FEV}_{1}$ and thus high flow during exercise, the larger 7-mm orifice was more appropriate (Fig. 6D). In the exercise study, care was taken to match the orifice size with the subject, the result was that the peak PEP pressures during exercise were $\sim 11 \mathrm{~cm}$ $\mathrm{H}_{2} \mathrm{O}$.

The conical-PEP breathing was found to be no more or less comfortable than the sham breathing. Five subjects stopped exercising before $10 \mathrm{~min}$ in the conicalPEP condition and 4 also stopped early in the sham condition, so it seemed that they had problems with the sensation of breathlessness in general rather than conical PEP in particular. The expiratory pressures generated by the older subjects were a little less than for the young subjects, but this was consistent with the lower expiratory flows of the older subjects. The pressures 
generated, however, were within the therapeutic range (Table 3).

It had been anticipated that the older subjects might develop hyperinflation during exercise and this could be minimized by conical-PEP breathing. There was a small reduction in inspiratory capacity at the end of the exercise (Table 3), which was similar in the conical-PEP and sham conditions, but this did not represent significant hyperinflation, which is usually defined by a reduction in inspiratory capacity of $>0.5 \mathrm{~L}$ at peak exercise in patients with mild $\mathrm{COPD}^{27}$ or $20 \%$ of resting vital capacity in patients with moderate-to-severe COPD. ${ }^{28,29}$ In our study, $20 \%$ of vital capacity was $\sim 0.54 \pm 0.01 \mathrm{~L}$ but inspiratory capacity was reduced by only $\sim 0.17 \mathrm{~L}$ in both conical-PEP and sham conditions. This indicated that the older subjects were healthy and had good lung function.

There was concern that resistance on the expiratory flow could lead to $\mathrm{CO}_{2}$ retention during exercise. With the apparatus (corrugated tube, bacterial filter, and flow transducer) used for the exercise testing, there was a dead space of $\sim 200 \mathrm{~mL}$, which could lead to an accumulation of $\mathrm{CO}_{2}$. However, conical PEP did not change $\mathrm{P}_{\mathrm{ETCO}_{2}}$ nor were there any differences in $\mathrm{S}_{\mathrm{pO}_{2}}$ compared with the sham. Although the overall pattern of breathing was unchanged when using the conical-PEP device, there was a tendency to prolong the expiratory phase, which would be advantageous in patients for whom slow expiration assists in the reduction of hyperinflation.

There were no adverse consequences of conical-PEP breathing during exercise or subsequent recovery; heart rate and blood pressure responses to exercise were not different in the conical-PEP and sham exercises, and neither did the healthy subjects in our study find that the added expiratory load affected their perceptions of respiratory effort. However, an unexpected, and unexplained, finding was that the rise in blood pressure at the end of exercise was reduced with conical-PEP breathing (Fig. 7C).

There were some limitations to this study. The mouthpiece used incorporated a one-way valve for the inspired air, and this had a certain resistance that may have contributed to the respiratory sensations reported by the subjects, but this was the same for both conical-PEP and sham conditions. At the highest flows, the tubing, bacterial filter, and respiratory transducer (Fig. 4B) increased peak expiratory pressure by $\sim 4 \pm 2 \mathrm{~cm} \mathrm{H}_{2} \mathrm{O}$, and this may have minimized the difference in terms of cardiopulmonary responses between conical PEP and sham results. Cycle exercise may not be a very good representation of the demands of everyday life, and it would be useful to assess the benefits of conical PEP during other types of exercise, such as treadmill exercise or when combining both upper and lower body exercise, which places greater demands on the respiratory system.

\section{Conclusions}

The orifice size and shape of an expiratory flow resistor affected the pressure-flow characteristics, with a larger orifice producing less pressure. The a conical-PEP device of 1-cm length with an orifice of 6 or $7 \mathrm{~mm}$ was found to generate pressures in the useful clinical range during mildto-moderate exercise in the young and older subjects. Further study is needed to incorporate the conical-PEP device into a mask and test its efficacy and safety with patients with COPD exercising and undergoing pulmonary rehabilitation.

\section{ACKNOWLEDGMENTS}

The authors thank the participants, Dr Watchara Boonsawat, the nurses, and the officers of the Respiratory Unit of Srinagarind Hospital, and the nurses and officers of Baan Nonmuang Health Promotion Hospital for their assistance in the conduction of this study. We thank Ms Malipron Pukdeechat, Mr Nontanat Sathaporn, Mr Khajonsak Pongpanit, Ms Philin Tongdee, Ms Netchanok Jianramas, and Ms Vatcharaporn Khaweephab for their assistance in extracting data for analysis.

\section{REFERENCES}

1. From the Global Strategy for the Diagnosis, Management and Prevention of COPD, Global Initiative for Chronic Obstructive Lung Disease (GOLD) 2017. Available from: https://goldcopd.org. Accessed October 31,2017.

2. O'Donnell DE, Laveneziana P. The clinical importance of dynamic lung hyperinflation in COPD. COPD 2006;3(4):219-232.

3. O'Donnell DE, Banzett RB, Carrieri-Kohlman V, Casaburi R, Davenport PW, Gandevia SC, et al. Pathophysiology of dyspnea in chronic obstructive pulmonary disease: a roundtable. Proc Am Thorac Soc 2007;4(2):145-168.

4. Groth S, Stafanger G, Dirksen H, Andersen JB, Falk M, Kelstrup M. Positive expiratory pressure (PEP-mask) physiotherapy improves ventilation and reduces volume of trapped gas in cystic fibrosis. Bull Eur Physiopathol Respir 1985;21(4):339-343.

5. McIlwaine M, Button B, Dwan K. Positive expiratory pressure physiotherapy for airway clearance in people with cystic fibrosis. Cochrane Database Syst Rev 2015;(6):CD003147.

6. Mestriner RG, Fernandes RO, Steffen LC, Donadio MV. Optimum design parameters for a therapist-constructed positive-expiratorypressure therapy bottle device. Respir Care 2009;54(4):504-508.

7. Monteiro MB, Berton DC, Moreira MA, Menna-Barreto SS, Teixeira PJ. Effects of expiratory positive airway pressure on dynamic hyperinflation during exercise in patients with COPD. Respir Care 2012;57(9):1405-1412.

8. van der Schans CP, de Jong W, de Vries G, Kaan WA, Postma DS, Koëter GH, van der Mark TW. Effects of positive expiratory pressure breathing during exercise in patients with COPD. Chest 1994; 105(3):782-789.

9. Martin AD, Davenport PW. Extrinsic Threshold PEEP Reduces Postexercise Dyspnea in COPD Patients: A Placebo-controlled, Doubleblind Cross-over Study Cardiopulm Phys Ther J 2011;22(3):5-10.

10. Pongpanit K, Boonsawat W, Jones D, Jones C. Positive expiratory pressure breathing increases the recovery of dyspnea in patients with COPD. Thai J Phys Ther 2015;37(1):41-53.

11. Nicolini A, Merliak F, Barlascini C. Use of positive expiratory pressure during six minute walk test: results in patients with moderate to 


\section{Conical PeP Device During Exercise}

severe chronic obstructive pulmonary disease. Multidiscip Respir Med 2013;8(1):19.

12. Russo D, Simonelli C, Paneroni M, Saleri M, Piroddi IM, Cardinale $\mathrm{F}$, et al. Is there an optimal level of positive expiratory pressure (PEP) to improve walking tolerance in patients with severe COPD? Archivos de bronconeumologia 2016;52(7):354-360.

13. Padkao T, Boonsawat W, Jones CU. Conical-PEP is safe, reduces lung hyperinflation and contributes to improved exercise endurance in patients with COPD: a randomised cross-over trial. J Physiother 2010;56(1):33-39.

14. Bhatt SP, Peterson MW, Wilson JS, Durairaj L. Noninvasive positive pressure ventilation in subjects with stable COPD: a randomized trial. Int J Chron Obstruct Pulmon Dis 2013;8:581-589.

15. Wibmer T, Rüdiger S, Heitner C, Kropf-Sanchen C, Blanta I, Stoiber $\mathrm{KM}$, et al. Effects of nasal positive expiratory pressure on dynamic hyperinflation and 6-minute walk test in patients with COPD. Respir Care 2014;59(5):699-708.

16. Gellish RL, Goslin BR, Olson RE, McDonald A, Russi GD, Moudgil VK. Longitudinal modeling of the relationship between age and maximal heart rate. Med Sci Sports Exerc 2007;39(5):822-829.

17. ATS Committee on Proficiency Standards for Clinical Pulmonary Function Laboratories. ATS statement: guidelines for the six-minute walk test. Am J Respir Crit Care Med 2002;166(1):111-117.

18. Miller MR, Hankinson J, Brusasco V, Burgos F, Casaburi R, Coates A, et al; ATS/ERS Task Force. Standardisation of spirometry. Eur Respir J 2005;26(2):319-338.

19. Morris JF. Spirometry in the evaluation of pulmonary function. West J Med 1976;125(2):110-118.

20. Fagevik Olsén M, Carlsson M, Olsén E, Westerdahl E. Evaluation of Pressure Generated by Resistors From Different Positive Expiratory Pressure Devices. Respir Care 2015;60(10):1418-1423.
21. Myers TR. Positive expiratory pressure and oscillatory positive expiratory pressure therapies. Respir Care 2007;52(10):1308-1326; discussion 1327.

22. AARC clinical practice guideline. Use of positive airway pressure adjuncts to bronchial hygiene therapy. American Association for Respir Care. Respir Care 1993;38(5):516-521.

23. Mancebo J, Albaladejo P, Touchard D, Bak E, Subirana M, Lemaire F, et al. Airway occlusion pressure to titrate positive end-expiratory pressure in patients with dynamic hyperinflation. Anesthesiology 2000;93(1):81-90.

24. Smith TC, Marini JJ. Impact of PEEP on lung mechanics and work of breathing in severe airflow obstruction. J Appl Physiol 1988; 65(4): 1488-1499.

25. Sydow M, Golisch W, Buscher H, Zinserling J, Crozier TA, Burchardi H. Effect of low-level PEEP on inspiratory work of breathing in intubated patients, both with healthy lungs and with COPD. Intensive Care Med 1995;21(11):887-895.

26. Fagevik Olsén M, Lannefors L, Westerdahl E. Positive expiratory pressure - Common clinical applications and physiological effects. Respir Med 2015;109(3):297-307.

27. Ofir D, Laveneziana P, Webb KA, Lam YM, O’Donnell DE. Mechanisms of dyspnea during cycle exercise in symptomatic patients with GOLD stage I chronic obstructive pulmonary disease. Am J Respir Crit Care Med 2008;177(6):622-629.

28. Maltais F, Hamilton A, Marciniuk D, Hernandez P, Sciurba FC, Richter K, et al. Improvements in symptom-limited exercise performance over $8 \mathrm{~h}$ with once-daily tiotropium in patients with COPD. Chest 2005;128(3):1168-1178.

29. O'Donnell DE, Flüge T, Gerken F, Hamilton A, Webb K, Aguilaniu B, et al. Effects of tiotropium on lung hyperinflation, dyspnoea and exercise tolerance in COPD. Eur Respir $J$ 2004;23(6):832-840.

This article is approved for Continuing Respiratory Care Education credit. For information and to obtain your CRCE

(free to AARC members) visit www.rcjournal.com

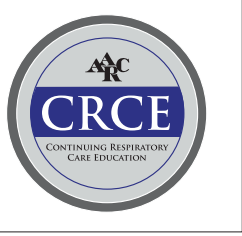

